\title{
INFANTILE SPASMS
}

\section{GUIDELINE UPDATE TO TREATMENT OF INFANTILE SPASMS}

The Guideline Developmental Subcommittee of the AAN and the Practice Committee of the CNS update the 2004 practice parameter on treatment of infantile spasms (IS). Based on 68 articles from 2002 to 2011:

1) Low-dose $\mathrm{ACTH}$ is probably as effective and should be considered as an alternative to high-dose $\mathrm{ACTH}$;

2) $\mathrm{ACTH}$ is more effective than vigabatrin (VGB) for short-term treatment (excluding patients with tuberous sclerosis complex);

3) Shorter lag time to treatment with either hormonal therapy or VGB possibly improves long-term developmental outcome;

4) Successful short-term treatment of cryptogenic IS with ACTH or prednisolone has better long-term developmental outcome than treatment with VGB;

5) $\mathrm{ACTH}$ is the preferred corticosteroid, and evidence is insufficient to recommend prednisolone, dexamethasone, and methylprednisolone as being as effective as ACTH for short-term treatment of IS; and

6) Evidence is insufficient to support the use of agents other than ACTH and VGB.

(Go CY, Mackay MT, Weiss SK et al. Evidence-based guideline update: Medical treatment of infantile spasms: Report of the Guideline Development Subcommittee of the American Academy of Neurology and the Practice Committee of the Child Neurology Society. Neurology 2012 June 12;78:1974-1980). (Response and reprints: American Academy of Neurology, E-mail: guidelines@aan.com).

COMMENT. The 2004 AAN/CNS parameter on the medical treatment of IS concluded that ACTH is probably effective for short-term therapy of IS and VGB is possibly effective for short-term therapy of IS and for treatment of children with tuberous sclerosis. In 2009, the USFDA approved VGB for use in IS and as add-on therapy for refractory seizures. In a single large Class III randomized controlled trial comparing lowdose and high-dose VGB, spasm cessation within 14 days was significantly higher in the high-dose group than low-dose $(15.9 \%$ vs $7 \% ; \mathrm{p}=0.03)$. In the symptomatic tuberous sclerosis complex group, spasm-free rate was higher with high-dose VGB $(25 \%$ vs $16.7 \%$ ). Hypsarrhythmia resolution was obtained in $30.8 \%$ patients on high dose VGB vs 13.2\% on low-dose VGB. (Elterman RD et al. J Child Neurol 2010;25:1340-1347).

Immunoglobulin treatment for West syndrome and other refractory epilepsies. In a trial of intravenous immunoglobulin to treat severe childhood epilepsy, full or partial improvement was obtained in 3 of 4 with idiopathic West syndrome, and in 6 of 12 patients with ESES. (Geva-Dayan K et al. Pediatr Neurol 2012 June;46:375381). IV immunoglobulin was ineffective in 10 patients with symptomatic West syndrome, 3 with myoclonic-astatic epilepsy, and 2 with Lennox- Gastaut syndrome. Of 19 responders (30\% of total severe epilepsies) 8 relapsed. 